\title{
FACTORS AFFECTING VIRTUAL GIFT ACCEPTANCE: MEDIATING ROLES OF HEDONIC AND UTILITARIAN VALUES
}

\author{
Eric M. Tamandja, Dakota State University, tamandja@gmail.com \\ Assion Lawson-Body, University of North Dakota, alawsonbody@business.und.edu \\ Laurence Lawson-Body, University of North Dakota, laurence.lawsonbody@business.und.edu \\ Jun Liu, Dakota State University, jun.liu@dsu.edu
}

\begin{abstract}
There is little formalized knowledge of virtual gifting in the information technology (IT) literature. The objective of this paper is to explore the factors affecting the acceptance of virtual gifts and specifically the factors within a virtual gift that affect individuals' intention to accept it and the mediating role of these factors. This research combines several acceptances, hedonic and utilitarian view related theories to explore the factors affecting acceptance of virtual gifts. Moreover, this study investigates the effects of usefulness, beautifulness, subjective norms of the receiver, and importance of the giver of a virtual gift as determinants of its utilitarian or/and hedonic value. The study finally examines the impact of the normative quality of the giver on the appropriateness of the virtual gift. A proposed research model will be tested using survey data and PLS (Partial least square). The implications of the research will be discussed.
\end{abstract}

Keywords: Virtual gifts, Perceived beautifulness, Hedonic value, Utilitarian value, IT acceptance, Normative quality.

\section{INTRODUCTION}

Virtuality plays an important role in individuals everyday lives (Chudoba, Wynn, Lu, \& Watson-Manheim, 2005). The art of gifting is a part of social behavior associated with human interactions. Social media updates individuals on friend and family celebrations such as birthdays, wedding anniversaries, etc. On those anniversaries, individuals send gifts or "something nice" to the concerned friend or family member in order to maintain social relationships and express feeling (Camerer, 1988). Gifting is a cultural, social, and economic communication material that is inherent across human societies. Gifting in the virtual world is a phenomenon whereby individuals purchase virtual products to give to others. The phenomenon is increasing as social network platforms are fulfilling this demand by creating the opportunity for users to acquire virtual gifts and be able to give them to their friends and relatives.

A perfect gift (Belk, 1996) may hold several types of value including economic, functional, social, expressive and sentimental and its topology includes monetary gift and non-monetary gift (Waldfogel, 2002). There are a large number of people who do not want to accept virtual gifts. Cruz-Cárdenas et al, (2015) found that recipients use 37.8\% of disliked gifts, while do not use $62.2 \%$. Because flaws may derive from gift's delivery or from the gift itself (Roster \& Amann, 2003; cited in Cruz-Cárdenas et al, 2015). This scenario might be relevant with the vulnerability of social media platforms. Acceptance of virtual gift's delivery might make the recipient social media account vulnerable.

Recipients who dislike gifts, probably storing or rejecting them. Therefore to use or not to use a disliked gift is a dilemma for recipients (Cruz-Cárdenas et al, 2015). In reality, human beings often receive and accept gifts from people they don't know or don't like, simply because it's easier than having a confrontation over rejecting the gift. We get something we don't want, or get something from a certain person we'd rather not receive from, and instead of going to the pain of rejecting, we accept the gift, often feigning gratitude, and then give it to someone else or discard it entirely.

The choice of the receiver will affect his relationship with the giver as well as marketing and business (Cruz-Cárdenas et al, 2015). In virtual gifting, won't the barrier to this type of passive acceptance be even easier--accept and discard rather than reject and risk confrontation? Virtual gift exchanges might not necessary satisfy receivers. Acceptance of virtual gifts out of a desire to not offend the giver is easier. In virtual gifting encounter, there is no physical confrontation between the giver and the recipient. Any body language, feeling or sentiment from the recipient is 


\section{Issues in Information Systems}

Volume 18, Issue 1, pp. 156-163, 2017

visible. The intention to accept, dislike, reject virtual gifts will not affect the relationship between the giver and the recipient. The giver could not know if the recipient decides to re-gift or send the gift to another person.

However, using a disliked gift may provide feedback to the giver (Cruz-Cárdenas et al, 2015). This scenario is also possible in the case of virtual gifting because the giver has an opportunity to detect online whether or not the recipient use the gift. Not using the gift would deteriorate the relationship while using the gift would protect the relationship (Cruz-Cárdenas et al, 2015).

A gift may have utilitarian quality (pragmatic), hedonic quality and normative quality. A gift's hedonic quality refers to the user's perception of the gift. Utilitarian value focuses on the efficiency to reach the desired information online while hedonic value focuses on fun, playfulness, and emotional worth (Etemad-Sajadi \& Ghachem, 2015). Perceived normative quality is how the importance of the virtual gift depends on the credibility and image of the giver. The shift from real material gifting to virtual gifting has led to a potentially lucrative source of revenue for virtual gift shops and increasing interest for researchers. Research in virtual gifting behavior is known to be constrained by the difficulty of obtaining data from individual behavior in the complex dynamic virtual world (Schultze \& Orlikowski, 2010).

The main issue that needed to be addressed in this paper is to design by looking at the motivations, social practice, and technical use of gifting communities. Anecdotally, there is an observation that social media platforms are encouraging users to use real world currency to purchase virtual items as gifts. However, there is little formalized knowledge of virtual gifting (Goode, Shailer, Wilson, \& Jankowski, 2014). From researchers' perspective and for the profit of practitioners, we draw from the literature three research questions on virtual gifting to address these unsolved issues:

RQ1: What are the requirements for a virtual gift to be accepted?

RQ2: How can a virtual gift be better designed to be accepted by the receiver?

RQ3: How can hedonic and utilitarian values of virtual gifts mediate the relationships among constructs from the technology acceptance model (TAM)?

The objective of this paper is to explore the factors affecting the acceptance of virtual gifts and specifically the factors within a virtual gift that affect individuals' intention to accept it. This research combines hedonic and utilitarian view related theories to explore their mediating relationships among factors from the TAM. Moreover, this study investigates the effects of usefulness, beautifulness, subjective norms of the receiver, and importance of the giver of a virtual gift as determinants of its utilitarian or/and hedonic value. The study finally examines the impact of the normative quality of the giver on the appropriateness of the virtual gift. Overall, this research is to understand the characteristics of virtual gifts in the perspective of acceptance by the receiver and how these can be implemented in the design of a perfect virtual gift. The rest of the paper is organized as follows. Theoretical background, research model and propositions, and methodology follow in subsequent sections and the conclusion section.

\section{THEORETICAL BACKGROUND}

This study rests on the premise that the definition, understanding, and measurement of theoretical concepts are not separated from the body of theory to which they can be associated (Smokler \& Hempel, 1966). Thus, any discussion of the virtual gift acceptance model should be cognizant of the theory of TAM (Davis Jr, 1986). We will use the overarching theory of TAM to develop the factors affecting virtual gift. We will develop propositions to address our research questions that are derived from logical explanations and from the literature. Figure 1 provides paths to be estimated and hypotheses to be tested. TAM is derived from the theory of reasoned action that measures the ability to predict people's computer acceptance behavior (Fishbein \& Ajzen, 1975). The original constructs of TAM include: perceived usefulness, perceived ease of use, and behavioral intention, which are assessed in the research model developed in this study. Some of the previous technology acceptance scales pay attention to hedonic and utilitarian 


\section{Issues in Information Systems}

Volume 18, Issue 1, pp. 156-163, 2017

dimensions and have empirically validated the positive effect of utilitarian and hedonic values on consumer behavior intention (Hong et al., 2017).

Hong et al. (2017)'s study suggests that hedonic and utilitarian constructs are two distinct dimensions of consumer attitude toward buyers' intention. Wu and Holsapple (2014) found that determinants of behavior may differ in using pleasure-oriented versus productivity-oriented IT (Wu \& Holsapple, 2014). As a matter of fact, Davis (1989) revealed that utilitarian value is not the most important determinant influencing behavioral intention to use an IT. Many consumers view hedonic dimension as the driver to adopt products for affective reasons, such as to delight in the newness of the product and to enjoy feelings of joy and satisfaction (Hong et al., 2017). Utilitarian value refers to the goal-oriented, rational, and functional purpose when using a product, whereas hedonic value implies the enjoyment being the primary benefit of customer acceptance of service or product (Wu and Holsapple, 2014; Hong et al., 2017).

\section{RESEARCH MODEL AND PROPOSITIONS}

We suggest that both utilitarian value (pragmatic quality) and hedonic value (enjoyment) influence the receiver's intention to accept a virtual gift. In addition normative quality influences the perception of appropriateness of the virtual gift, which in turn influences intention to accept a virtual gift. The normative quality bears on the importance and image of the giver; therefore the appropriateness, which includes the design and the value of the gift, should reflect the importance of the giver. In other words, the perceived usefulness is mediated by the utilitarian value (pragmatic quality) and the hedonic value of the virtual gift. Specifically, perceived usefulness should be positively correlated to the utilitarian value and the hedonic value, which should both be positively correlated to the intention to accept the virtual gift. The perceived beautifulness is mediated by the hedonic value of the virtual gift. Both should be positively correlated to the intention to accept the virtual gift. Subjective norms should influence hedonic value, which mediates its relationship with intention to accept the virtual gift.

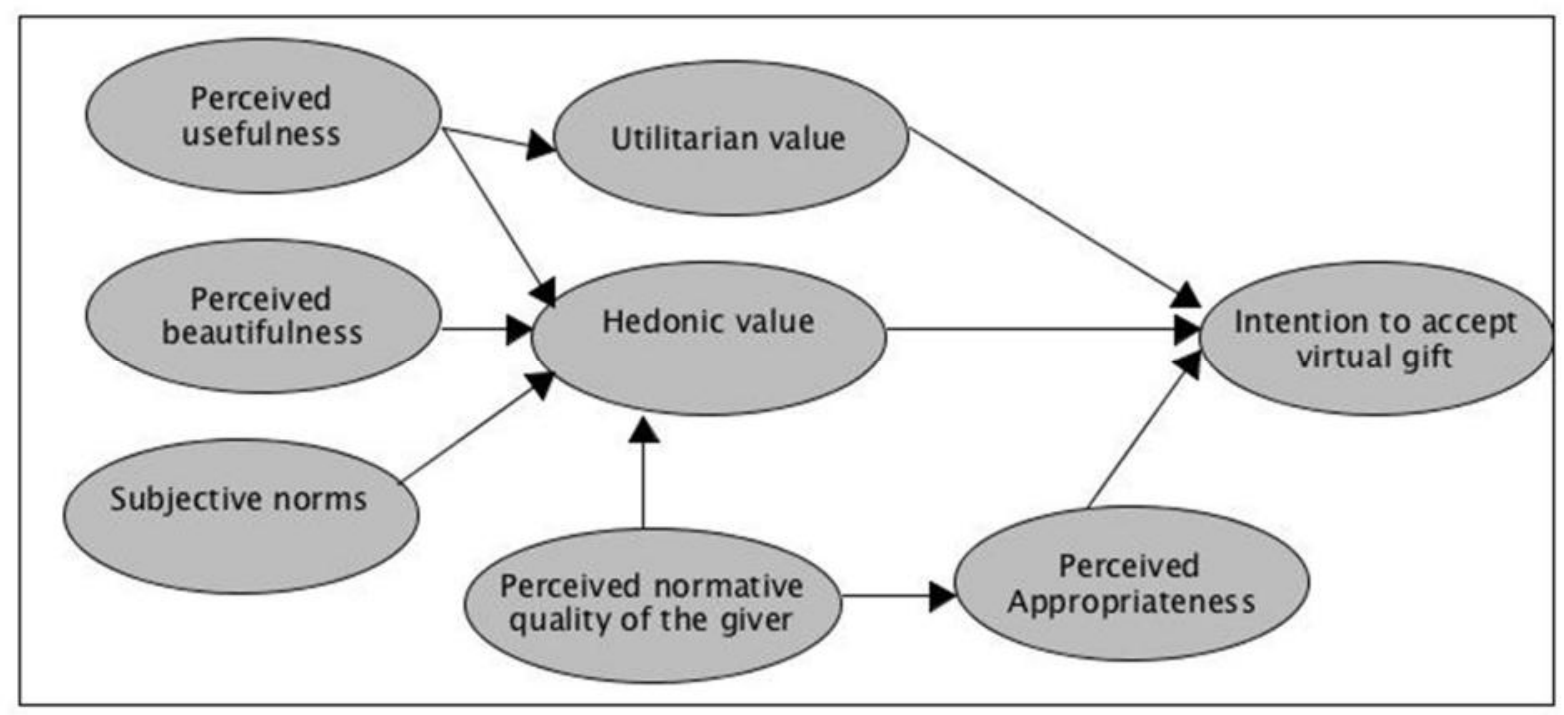

Figure 1. Virtual Gift Acceptance Model

\section{Perceived Usefulness of a Virtual gift and Utilitarian Value}

A Usefulness of a virtual gift is connected to utilitarian value or pragmatic quality which is associated with the user's need to achieve behavioral goals (Hassenzahl, Burmester, \& Koller, 2003). A gift is perceived to be useful (having 
utilitarian value) to the receiver if there is a perception of utility and usability. A receiver may consider a gift appropriate and acceptable if the expected utility function is perceived. Let $\operatorname{Umag}(\mathrm{V}, \delta)$ be the utility function where $\mathrm{V}$ is the material value of the gift and $\delta$ the perceived usefulness. $\delta$ is equivalent to $(\mathrm{P})$ when useful or $(\mathrm{N})$ when nonuseful. The receiver accepts the gift if the expected utility (EUmag) function of perceived useful EUmag $(\mathrm{V}, \mathrm{P})>$ EUmag $(\mathrm{V}, \mathrm{N})$, therefore a virtual gift must bear some sort of expected value denoted emotional utility. Utility factors have been touted as an important determinant of behavioral intention to accept to use specific technology (Venkatesh, Morris, Davis, \& Davis, 2003). An emotional utility is demonstrated if the virtual gift has the capability of changing the receiver's mood at reception (utility) and if it can be used another time for the same reason (usability). The nature of the gift does not matter as long as it matches the receiver needs. We believe that perceived usefulness of a virtual gift will positively influence the utilitarian value of the gift and the utilitarian value of a virtual gift will positively influence the intention to accept the gift.

Proposition 1: Perceived usefulness of a virtual gift positively influences the utilitarian value of the gift.

Proposition 2: Utilitarian value of the gift positively influences the intention to accept the virtual gift.

\section{Perceived Usefulness of a Virtual gift and Hedonic Value}

Perceived usefulness is identified as the most influential antecedent of individuals' intention to use technologies (Davis Jr, 1986). Perceived usefulness reflects the utilitarian nature of productivity-oriented systems. It also refers to the degree to which a person believes that using an IT would enhance his or her job or task performance (Wu \& Holsapple, 2014). Furthermore, perceived usefulness is an individual's belief that the use of technology will improve performance. However, the virtual world and many of the online delivery technologies integrated into our daily lives have substantial pleasure-oriented (or hedonic) qualities and are mainly used for fun and relaxation (Wu \& Holsapple, 2014). Typical examples of such technologies are virtual gifts, which aim to provide pleasure or hedonic value to the receivers. We suggest using perceived usefulness, which is originally conceptualized for utilitarian systems in workplace settings (Wu and Holsapple, 2014) to explain the usage of such pleasure-oriented systems of virtual gifts. Therefore, we follow Hong et al. (2017) who mentioned that IT acceptance and behavioral intention are influenced by both perceived usefulness and hedonic value (perceived enjoyment).

Proposition 3: Perceived usefulness of a virtual gift positively influences the hedonic value of the gift.

Proposition 4: Hedonic value of a virtual gift positively influences the intention to accept the gift.

\section{Perceived Beautifulness of a Virtual gift and Hedonic Value}

Perceived beautifulness refers to the extent to which a gift can provide physical attractiveness to the receiver. Dion et al. (1972) conducted a study on people physical appearance and their success in life and concluded that what is beautiful is good (Dion, Berscheid, \& Walster, 1972). A material gift's beautifulness quality bears on how the gift can be attractive to the receiver. People exclaim "beautiful" meaning "great" or "wonderful" or "I like that a lot." A beautyclaim is essentially the claim that the thing in question is worthy of being aesthetically admired. A beautiful virtual gift possesses qualities that give greater pleasure or satisfaction to see, to hear or to think about. In social sciences, it is widely accepted that beauty is socially constructed according to time and space and what is beautiful is usable (Tractinsky, Katz, \& Ikar, 2000). A gift that is perceived as beautiful can be novel or challenging which has hedonic stimulation quality and when it communicates personal value and self-presentational function, it has hedonic identification quality (Hassenzahl, 2004). Therefore, we suggest that beautifulness is associated with the hedonic value of the virtual gift.

Proposition 5: Perceived beautifulness of a virtual gift positively influences the hedonic value of the gift

\section{Perceived Normative Quality of the Giver}

A gift is a symbolic declaration about the giver, the receiver and the relationship connecting them. Sherry (1983) describes gift giver motivations as agonistic intention as centering on power and focusing on the enhancement of the 
giver (Sherry, 1983). Perceived normative quality of the giver refers to the extent to which the receiver appreciates the gift based on the sender's social status or belief. A strong tie between the giver and the receiver is necessary for the exchange to take place and all gift giving must be explored within this relationship. These perceptions can be evaluated by analyzing the perceived normative quality of the giver, which is associated with the importance of the giver. Evidence suggests that importance of social status is in relation to gifting behavior (Goode et al., 2014). Gifting cannot occur outside of a relationship (Larsen \& Watson, 2001). The phenomenon of virtual gifting can occur in networked relationships. Strong ties can be measured by the frequency of interactions, the nature of the relationships, and other social considerations (Granovetter, 1973; Levin \& Cross, 2004). Gulati's (1998) study uses tie strength to analyze trust, which denotes the importance of both members in the relationship (Gulati, 1998). Having a close relationship with a member of a network might mean there is a trust relationship and thus, high normative quality. We believe that perceived normative quality of the giver influences the hedonic value and contribute to the perception of appropriateness of a gift.

Proposition 6: Perceived normative quality of the giver of a virtual gift influences the hedonic value of the gift.

Proposition 7: Perceived normative quality of the giver influences the perception of appropriateness of the gift.

\section{Subjective Norms of the Receiver and Hedonic Value}

Subjective norms refer to "the person's perception that most people who are important to him think he should or should not perform the behavior in question" (Fishbein and Ajzen 1975, p.302). In terms of virtual gift acceptance, the receiver should enjoy the virtual gift because his friends, family, and colleagues/peers also receive virtual gifts and enjoy those. Individuals who are related or close to the virtual gift receiver enjoy, talk, and appreciate virtual gifts; that will create internal stimulus for the gift receiver who should live in the expectation of receiving a virtual gift. Therefore, subjective norms of the gift receiver can influence the hedonic value of the gift. The receiver should enjoy virtual gifts simply because his friends attach a high importance to virtual gifts. Subjective norms are also related to intention because people often act based on their perception of what others think they should do. Previous studies found a significant influence of subjective norms on behavioral intention to use an IT (Schepers \& Wetzels, 2007). Because people who are close to the receiver accept virtual gifts, they should be influenced by those people's behavior and incline to accept virtual gifts. Although, there is no basis on which to predict how each of these groups will affect intention to accept virtual gifts. This suggests hedonic value should mediate the relationship between subjective norms and intention to accept virtual gifts.

Proposition 8: Subjective norms of the receiver of a virtual gift influence the hedonic value of the gift.

Proposition 9: Hedonic value of the gift mediates the relationship between subjective norms and intention to accept a virtual gift.

\section{Perceived Appropriateness of the gift}

In reference for gifting behavior, intention to accept a material gift can be associated to its appropriateness, for example, in some circumstances, it's inappropriate to offer children's toys to an adult. Appropriateness of a gift refers to choosing a gift that is suitable for the receiver or that the receiver will appreciate (Belk, 1996). Virtual gifts will be useful and appropriated if they are designed to fit the image of the receiver (Belk, 1977). Also, the appropriateness of the virtual gift corresponds to the package, the size, the type and the value of the gift. The appropriateness of the gift has been related to the nature of the gift, which is used to explain the delivery process or mechanism of the gift. Some virtual gifts can be totally delivered and consumed online; whereas some can be delivered online but consume offline. For instance, foods and automobiles can be delivered online but their use or consummation will be done physically, whereas virtual flowers, music, games, movies, online learning, and birthday cards can be delivered and consumed online. Appropriateness is perceived as a key quality of the perfect gift. Therefore perceived appropriateness is associated with the intention to accept a virtual gift.

Proposition 10: Perceived appropriateness of a virtual gift influences the intention to accept a virtual gift 


\section{METHODOLOGY}

We will perform a survey on university students who are active social media users. The sample would consist of 124 business major students that have at least received one virtual gift within a year. In order to develop and validate the instrument, two steps will be taken with respect to survey design. We first will develop measures from the literature and perform an initial pretest. We will adapt existing measurement instruments because many authors have developed and validated measurement instruments of IT acceptance. For instance, intention to accept a virtual gift will be measured with five items adapted from Davis (Davis Jr, 1986).

A pretest will be conducted in order to assess the face validity of the instrument. Face validity is the extent to which an instrument is going to measure what it is intended to measure. We will perform a pretest for comprehensiveness and clearness using faculty, as well as graduate students trained in questionnaire design (Dillman, 1978). Our survey will be extensively reviewed and evaluated by the small group of faculty and students. The result of the pretest will be used to modify the size, the scope, and the length of the questionnaire.

The survey will contain multiple measurement items relating to each of the constructs in the research model. A sevenpoint Likert scale ranging from "strongly disagree" (1) to "strongly agree" (7) will be used to measure each construct: perceived usefulness, perceived beautifulness, utilitarian value, hedonic value, subjective norms, perceived normative quality, and perceived appropriateness of the virtual gift. We will use a Partial Least Squares (PLS) based structural equation modeling (Chin, 1998; Hair, 2010) to assess and analyze the items from the survey.

\section{CONCLUSION}

Given the lack of empirical research on usefulness, beautifulness, utilitarian value, hedonic value, subjective norms, and giver's importance as determinants of intention to accept a virtual gift, the findings of this study would contribute to extending the existing literature regarding the virtual gifting phenomenon. For the practical side, the expected results call virtual gifts designers' attention to the importance for matching perfect gift characteristics to virtual gift design. The expected results of the study suggest that as for both material gifts and virtual gifts, the reasons for accepting gifts of two different natures are most likely to be the same. Moreover, the conceptual framework provides a basis for future research to construct a theory for virtual gift acceptance. This study builds on the findings of other studies and should extend the TAM theory, the utilitarian theory and hedonic theory.

\section{REFERENCES}

Belk, R. W. (1977). Gift-giving behavior: College of Commerce and Business Administration, University of Illinois at Urbana-Champaign.

Belk, R. W. (1996). The perfect gift. Gift giving: A research anthology, 59-84.

Camerer, C. (1988). Gifts as economic signals and social symbols. American Journal of Sociology, S180-S214.

Chin, W. W. (1998). The partial least squares approach to structural equation modeling. Modern methods for business research, 295(2), 295-336.

Chudoba, K. M., Wynn, E., Lu, M., \& Watson-Manheim, M. B. (2005). How virtual are we? Measuring virtuality and understanding its impact in a global organization. Information Systems Journal, 15(4), 279-306. 
Davis Jr, F. D. (1986). A technology acceptance model for empirically testing new end-user information systems: Theory and results. Massachusetts Institute of Technology.

Dillman, D. A. (1978). Mail and telephone surveys (Vol. 3): Wiley Interscience.

Dion, K., Berscheid, E., \& Walster, E. (1972). What is beautiful is good. Journal of Personality and Social Psychology, 24(3), 285.

Etemad-Sajadi, R., \& Ghachem, L. (2015). The impact of hedonic and utilitarian value of online avatars on e-service quality. Computers in Human Behavior, 52, 81-86.

Fishbein, M., \& Ajzen, I. (1975). Belief, attitude, intention and behavior: An introduction to theory and research.

Goode, S., Shailer, G., Wilson, M., \& Jankowski, J. (2014). Gifting and Status in Virtual Worlds. Journal of Management Information Systems, 31(2), 171-210.

Granovetter, M. S. (1973). The strength of weak ties. American Journal of Sociology, 13601380.

Gulati, R. (1998). Alliances and networks. Strategic Management Journal, 19(4), 293-317.

Hair, J. F. (2010). Multivariate data analysis: a global perspective. Upper Saddle River, N.J. Pearson Education. $7^{\mathrm{TH}}$ Edition.

Hassenzahl, M. (2004). The interplay of beauty, goodness, and usability in interactive products. Human-Computer Interaction, 19(4), 319-349.

Hassenzahl, M., Burmester, M., \& Koller, F. (2003). AttrakDiff: Ein Fragebogen zur Messung wahrgenommener hedonischer und pragmatischer Qualität Mensch \& Computer 2003 (pp. 187-196): Springer.

Hong, J-C., Lin, P-H. \& Hsieh, P-C. (2017). The effect of consumer innovativeness on perceived value and continuance intention to use smartwatch Computers in Human Behavior, 67, 264-272.

Larsen, D., \& Watson, J. J. (2001). A guide map to the terrain of gift value. Psychology \& Marketing, 18(8), 889-906.

Levin, D. Z., \& Cross, R. (2004). The strength of weak ties you can trust: The mediating role of trust in effective knowledge transfer. Management science, 50(11), 1477-1490.

Schepers, J., \& Wetzels, M. (2007). A meta-analysis of the technology acceptance model: Investigating subjective norm and moderation effects. Information \& Management, 44(1), 90-103. 
Schultze, U., \& Orlikowski, W. J. (2010). Research commentary-virtual worlds: A performative perspective on globally distributed, immersive work. Information Systems Research, 21(4), 810-821.

Sherry, J. F. (1983). Gift giving in anthropological perspective. Journal of Consumer Research, 10(2), 157-168.

Smokler, H., \& Hempel, C. G. (1966). Aspects of Scientific Explanation and Other Essays in the Philosophy of Science: JSTOR.

Tractinsky, N., Katz, A. S., \& Ikar, D. (2000). What is beautiful is usable. Interacting with computers, 13(2), 127-145.

Venkatesh, V., Morris, M. G., Davis, G. B., \& Davis, F. D. (2003). User acceptance of information technology: Toward a unified view. MIS Quarterly, 425-478.

Waldfogel, J. (2002). Gifts, Cash, and Stigma. Economic Inquiry, 40(3), 415-427.

Wu, J., \& Holsapple, C. (2014). Imaginal and emotional experiences in pleasure-oriented IT usage: A hedonic consumption perspective. Information \& Management, 51(1), 80-92. 